\title{
Evidence for Role of Cytosolic Free Calcium in Hypoxia-induced Proximal Tubule Injury
}

Andreas Kribben, Eric D. Wieder, Jack F.M. Wetzels, Luis Yu, Patricia E. Gengaro, Thomas J. Burke, and Robert W. Schrier Department of Medicine, University of Colorado School of Medicine, Denver, Colorado 80262

\begin{abstract}
The role of cytosolic free $\mathrm{Ca}^{2+}\left(\left[\mathrm{Ca}^{2+}\right]_{i}\right)$ in hypoxic injury was investigated in rat proximal tubules. $\left[\mathrm{Ca}^{2+}\right]_{i}$ was measured using fura-2 and cell injury was estimated with propidium iodide (PI) in individual tubules using video imaging fluorescence microscopy. $\left[\mathrm{Ca}^{2+}\right]_{i}$ increased from $\sim 170$ to $\sim 390 \mathrm{nM}$ during $5 \mathrm{~min}$ of hypoxia. This increase preceded detectable cell injury as assessed by $P I$ and was reversible with reoxygenation. 1,2Bis(2-aminophenoxy)ethane- $N, N, N^{\prime}, N^{\prime}$-tetraacetic acid (BAPTA; $100 \mu \mathrm{M})$ reduced $\left[\mathrm{Ca}^{2+}\right]_{i}$ under basal conditions $(\sim 80 \mathrm{nM})$ and during hypoxia $(\sim 120 \mathrm{nM})$ and significantly attenuated hypoxic injury. When $\left[\mathrm{Ca}^{2+}\right]_{i}$ and hypoxic cell injury were studied concurrently in the same individual tubules, the 10 min $\left[\mathrm{Ca}^{2+}\right]_{i}$ rise correlated significantly with subsequent cell damage observed at $20 \mathrm{~min} .2 \mathrm{mM}$ glycine did not block the rise in $\left[\mathrm{Ca}^{2+}\right]_{i}$, yet protected the tubules from hypoxic injury. These results indicate that in rat proximal tubules, hypoxia induces an increase of $\left[\mathrm{Ca}^{2+}\right]_{i}$ which occurs before cell damage. The protective effect of BAPTA supports a role for $\left[\mathrm{Ca}^{2+}\right]_{i}$ in the initiation of hypoxic proximal tubule injury. The glycine results, however, implicate calcium-independent mechanisms of injury and/ or blockade of calcium-mediated processes of injury such as activation of phospholipases or proteases. (J. Clin. Invest. 1994.93:1922-1929.) Key words: propidium iodide • fura-2 • computer-assisted image processing • BAPTA • adenosine triphosphate
\end{abstract}

\section{Introduction}

Proximal tubules are an important site of injury during renal hypoxia (1). Intracellular $\mathrm{Ca}^{2+}$ has been suggested to be important in the mediation of this hypoxic injury $(1,2)$. However, support for this hypothesis has to date been indirect. For example, although hypoxia increases ${ }^{45} \mathrm{Ca}^{2+}$ uptake in isolated proximal tubules (3) and a time-dependent increase in total cell $\mathrm{Ca}^{2+}$, as assessed by atomic absorption, occurs in tubules during hypoxia $(4,5)$, whether this cellular $\mathrm{Ca}^{2+}$ overload is partly retained in the cytosol or completely accumulated by mito-

Parts of this work were presented at the 25th Meeting of the American Society of Nephrology, Baltimore, MD, November 1992, and at the 12th Meeting of the International Society of Nephrology, Jerusalem, June 1993.

Andreas Kribben's present address is the Division of Renal Diseases and Hypertension, Department of Internal Medicine, University of Essen, Hufelandstrasse 55, D-45147 Essen, Germany.

Address correspondence to Dr. Robert W. Schrier, Department of Medicine, C281, University of Colorado School of Medicine, $4200 \mathrm{E}$. 9th Avenue, Denver, CO 80262.

Received for publication 29 September 1993 and in revised form 4 January 1994.

J. Clin. Invest.

(C) The American Society for Clinical Investigation, Inc

$0021-9738 / 94 / 05 / 1922 / 08 \quad \$ 2.00$

Volume 93, May 1994, 1922-1929 chondria (4) is unknown. Additional evidence supporting a role for $\mathrm{Ca}^{2+}$ in cell injury is the fact that a reduction of extracellular $\mathrm{Ca}^{2+}$ during anoxia (4) or hypoxia (6) markedly attenuates cell injury. Also, the calcium channel blockers verapamil and flunarizine have been shown to delay the development of hypoxic injury in proximal tubules $(3,6)$. This protective effect was paralleled by a reduction of the increased rate of ${ }^{45} \mathrm{Ca}^{2+}$ uptake (3). It has also been shown that an increase in $\left[\mathrm{Ca}^{2+}\right]_{i}$, using the $\mathrm{Ca}^{2+}$ ionophore ionomycin, induces cell injury in normoxic cultured tubule cells (7) and in isolated proximal tubules (8).

In contrast, there are other studies that appear to support factors other than a rise in $\left[\mathrm{Ca}^{2+}\right]_{\mathrm{i}}$ in mediating cell injury. Some of these studies have induced ATP depletion by metabolic inhibitors, rather than by oxygen deprivation (9), whereas others have evaluated complete oxygen deprivation (anoxia) rather than hypoxia $(4,5,10)$. For example, ATP depletion was induced with either the mitochondrial uncoupler 1799 or the metabolic inhibitor cyanide and no significant early increase in $\left[\mathrm{Ca}^{2+}\right]_{\mathrm{i}}$ could be observed in rabbit proximal tubules $(8,10)$. However, under virtually identical conditions $\left[\mathrm{Ca}^{2+}\right]_{i}$ increased in rat proximal tubules (11). Because the experimental conditions characteristic of chemical ATP depletion do not completely mimic all of the events associated with injury induced by oxygen deprivation, these results might not be totally transferable to hypoxia. Secondly, in contrast to hypoxia, anoxia of rabbit tubules did not increase total cell $\mathrm{Ca}^{2+}(4,5)$, and no increase in $\left[\mathrm{Ca}^{2+}\right]_{i}$ was observed (10). Thus, even though species differences may account, in part, for the variable responses of $\left[\mathrm{Ca}^{2+}\right]_{\mathrm{i}}$ between rat and rabbit tubules, different mechanisms may also exist to account for the injury induced by hypoxia as compared to either anoxia or metabolic inhibitors, i.e., the socalled chemical hypoxia.

Based on these different results using different degrees of oxygen deprivation or chemical hypoxia in different species, it is not surprising that no consensus exists as to whether or not $\left[\mathrm{Ca}^{2+}\right]_{\mathrm{i}}$ increases in proximal tubules during hypoxia $(1,9)$. Moreover, if $\left[\mathrm{Ca}^{2+}\right]_{\mathbf{i}}$ increases during hypoxia, a question remains as to whether such an increase is of potential pathophysiological importance or is merely a result of the injury. Finally, many of the studies of renal tubules and the responses to anoxia or hypoxia have been conducted in suspensions of tubules wherein only the average responses of many tubules can be evaluated. To our knowledge, no investigation of the changes in $\left[\mathrm{Ca}^{2+}\right]_{i}$ in temporal relation with cell injury in individual, freshly isolated rat proximal tubules has heretofore been conducted during hypoxia induced by oxygen deprivation.

Recently, we perfected and described a video imaging system in which changes in $\left[\mathrm{Ca}^{2+}\right]_{i}$ and membrane damage, as assessed by the normally membrane-impermeable dye propidium iodide (PI), ${ }^{1}$ can be concurrently studied in individual

1. Abbreviations used in this paper: BAPTA-AM, acetomethylester of 1,2-bis(2-aminophenoxy)ethane- $N, N, N^{\prime}, N^{\prime}$-tetraacetic acid; CCB, calcium channel blocker; $\mathrm{CN}^{-}$, cyanide; $\mathrm{LDH}$, lactate dehydrogenase; PI, propidium iodide. 
freshly isolated rat proximal tubules (12). This technique has previously been used by others to study cell $\left[\mathrm{Ca}^{2+}\right]_{i}$ and cyanide-induced injury in cultured hepatocytes (13) and to study $\left[\mathrm{Ca}^{2+}\right]_{\mathrm{i}}$ and $\mathrm{HgCl}_{2}$-induced injury in rabbit proximal tubule cells (14). On entering the cell, the PI stains the nucleus and this staining correlates with the release of LDH from injured tubules in suspension (12). The perfusion chamber used in conjuction with the video imaging system permits the quantitative assessment of changes in cytosolic free $\mathrm{Ca}^{2+}$ and membrane permeability to $\mathrm{PI}$ in the same tubule in response to an hypoxic insult.

Thus, to determine if $\left[\mathrm{Ca}^{2+}\right]_{i}$ increases during hypoxia, and if so, whether it increases before the appearance of cell injury, we measured both $\left[\mathrm{Ca}^{2+}\right]_{i}$ and cell injury using video imaging fluorescence microscopy in individual freshly isolated rat proximal tubules subjected to hypoxia. In addition, a cause and effect relationship between the increased $\left[\mathrm{Ca}^{2+}\right]_{i}$ and the subsequent development of cell injury was examined $(a)$ by correlating early changes in $\left[\mathrm{Ca}^{2+}\right]_{i}$ with subsequent damage in the same individual tubules and $(b)$ by reducing the increase in $\left[\mathrm{Ca}^{2+}\right]_{\mathrm{i}}$ due to hypoxia with the intracellular $\mathrm{Ca}^{2+}$ chelator $1,2-$ bis(2-aminophenoxy)ethane- $N, N, N^{\prime}, N^{\prime}$-tetraacetic acid (BAPTA). Finally, we measured the effects of $2 \mathrm{mM}$ glycine on $\left[\mathrm{Ca}^{2+}\right]_{i}$ and cell injury during hypoxia, because glycine has been shown to prevent cell injury induced by metabolic inhibitors, ionophores, or hypoxic insults $(8,15-17)$.

\section{Methods}

Preparation of tubules. Proximal tubules were isolated from kidney cortex of male Sprague-Dawley rats (200-300 g) by collagenase digestion and isopycnic centrifugation on Percoll gradients as described elsewhere $(3,6)$. The tubules were suspended in a $95 \% \mathrm{O}_{2} / 5 \% \mathrm{CO}_{2}$ gassed buffer containing (in $\mathrm{mM}$ ) $\mathrm{NaCl} 106, \mathrm{NaHCO}_{3} 25, \mathrm{KCl} \mathrm{5,} \mathrm{CaCl}{ }_{2}$, $\mathrm{Na}_{2} \mathrm{HPO}_{4} 2, \mathrm{MgSO}_{4} 1$, glucose 5, Hepes 2.5, glutamine 2, sodium butyrate 10 , and sodium lactate 4 . Aliquots $(3-6 \mathrm{ml}$ containing $\sim 1.0-1.5$ $\mathrm{mg}$ protein $/ \mathrm{ml}$ ) were placed in siliconized Erlenmeyer flasks $(25 \mathrm{ml})$ and gassed on ice for $5 \mathrm{~min}$ with $95 \% \mathrm{O}_{2} / 5 \% \mathrm{CO}_{2}$. Thereafter the flasks were capped with rubber stoppers and kept on ice until use.

Induction of hypoxia. The effects of hypoxia were studied both in individual tubules using video imaging fluorescence microscopy as well as in tubule suspensions. In individual tubules, hypoxia was induced in a customized microperfusion chamber as previously described (12). Briefly, the tubule suspension was diluted $1: 1$ with a bicarbonate perfusion buffer. The perfusion buffer was gassed at room temperature with $95 \% \mathrm{O}_{2} / 5 \% \mathrm{CO}_{2}\left(\mathrm{O}_{2}\right.$ gassed buffer) and contained (in $\left.\mathrm{mM}\right) \mathrm{NaCl} 113$, $\mathrm{NaHCO}_{3} 18, \mathrm{KCl} \mathrm{5}, \mathrm{CaCl}_{2} 1, \mathrm{Na}_{2} \mathrm{HPO}_{4} 2, \mathrm{MgSO}_{4} 1$, glucose 5, glutamine 1 , sodium butyrate 1 , and sodium lactate $1(\mathrm{pH} 7.35-7.40$ in the presence of $5 \% \mathrm{CO}_{2}$ at $37^{\circ} \mathrm{C}$ ). An aliquot of this tubule suspension was pipetted onto a Cell-Tak-coated glass coverslip, which was mounted at the base of the microperfusion chamber. This chamber was affixed to the stage of an inverted epifluorescence microscope (Diaphot; Nikon Inc., Garden City, NY). The $\mathrm{O}_{2}$-gassed buffer in the chamber was superfused with $95 \% \mathrm{O}_{2} / 5 \% \mathrm{CO}_{2}$ at room temperature for $10 \mathrm{~min}$ to maintain the $\mathrm{pO}_{2}(\sim 400 \mathrm{mmHg})$ and $\mathrm{pH}(\sim 7.2)$ while the tubules settled and attached to the coverslip. The chamber was then perfused continuously with $\mathrm{O}_{2}$-gassed buffer at $2 \mathrm{ml} / \mathrm{min}$ for $10 \mathrm{~min}$ and the temperature gradually increased to $36-37^{\circ} \mathrm{C}$ with an air stream stage incubator (Nicholson Precision Instruments, Bethesda, MD). Hypoxia was induced by switching to a bicarbonate perfusion buffer pregassed with $95 \% \mathrm{~N}_{2} / 5 \% \mathrm{CO}_{2}\left(\mathrm{~N}_{2}\right.$-gassed $)$ at $37^{\circ} \mathrm{C}(t=0 \mathrm{~min})$. The buffer was also superfused in the chamber with $95 \% \mathrm{~N}_{2} / 5 \% \mathrm{CO}_{2}$ gas. Under these conditions, the $\mathrm{PO}_{2}$ of the perfusate fell rapidly and stabilized at 10 $\mathrm{mmHg}$ at the entrance of the chamber as measured by a flow-through $\mathrm{O}_{2}$-electrode (Microelectrodes Inc., Londonderry, NH). Hypoxia was also confirmed by observing an increase in the $450 \mathrm{~nm}$ autofluorescence ( $357 \mathrm{~nm}$ excitation) within $1 \mathrm{~min}(118 \pm 5 \%$ of basal, $P<0.05, n$ $=4$ experiments); after 2 min the autofluorescence had increased further $(133 \pm 4 \%$ of basal, $P<0.01, n=4)$. These data reflect an increase of intracellular NADH (18).

In control experiments, the chamber was continuously perfused with $\mathrm{O}_{2}$-gassed buffer (continued normoxia) in combination with superfusion of $95 \% \mathrm{O}_{2} / 5 \% \mathrm{CO}_{2}$. $\left[\mathrm{Ca}^{2+}\right]_{i}$ and cell damage were measured before, during, and after hypoxia or continued normoxia using fura-2 and the membrane-impermeable dye PI, respectively, as described below.

For studies performed in tubule suspensions, hypoxia was induced in Erlenmeyer flasks as previously described $(3,6)$. Briefly, flasks containing 6-7 ml of tubule suspensions were gassed on ice for $5 \mathrm{~min}$ with $95 \% \mathrm{O}_{2} / 5 \% \mathrm{CO}_{2}$, sealed, and then placed in a shaking waterbath at $37^{\circ} \mathrm{C}$ for the remainder of the experiment. After a warming period of $10 \mathrm{~min}$ the $\mathrm{pH}$ had risen to $7.35 .1 \mathrm{ml}$ of tubule suspension was sampled for measurement of baseline lactate dehydrogenase (LDH) release (see below), and experiments were continued. Hypoxia was induced $(t$ $=0 \mathrm{~min}$ ) by gassing the tubule suspension for $5 \mathrm{~min}$ with $95 \% \mathrm{~N}_{2} / 5 \%$ $\mathrm{CO}_{2}$. Control tubules were gassed for $5 \mathrm{~min}$ with $95 \% \mathrm{O}_{2} / 5 \% \mathrm{CO}_{2}$. After gassing, flasks were resealed. At $t=15 \mathrm{~min}$, samples for LDH measurement were taken. Samples were also taken for measurement of ATP and intracellular potassium.

In other experiments, tubule suspensions were gassed with 95\% $\mathrm{O}_{2} / 5 \% \mathrm{CO}_{2}$ for $5 \mathrm{~min}$ and then incubated for $45 \mathrm{~min}$ at room temperature with varying concentrations of BAPTA-acetomethylester (AM), added from a $10 \mathrm{mM}$ stock solution in dry DMSO. These tubules, loaded with BAPTA to chelate $\left[\mathrm{Ca}^{2+}\right]_{i}$, were then studied as described above either in the microperfusion chamber or in suspension in flasks after being returned to the $37^{\circ} \mathrm{C}$ shaking waterbath. Non-BAPTAloaded tubules were treated identically and served as experimental controls. Other experiments were conducted in which the perfusion buffer contained either glycine $(2 \mathrm{mM})$, verapamil $(100 \mu \mathrm{M})$, or low $\mathrm{Ca}^{2+}$ buffer ( $1 \mathrm{mM}$ EGTA, $0.7 \mathrm{mM} \mathrm{Ca}^{2+}$ ). We have previously used these concentrations in the study of isolated rat tubules in suspension $(3,6$, 17). These studies are our first in evaluating their effects in a perfusion chamber.

Video imaging fluorescence microscopy: general. The studies of individual tubules were undertaken and analyzed with a customized imaging system (S\&M Microscopes, Colorado Springs, CO) as described previously (12). All images were acquired with an intensified chargecoupled device camera (CCD; Genisys Intensifier, CCD72 camera; Dage-MTI Inc., Michigan City, IN) and processed through an IBM PC/AT computer using image processing software (Image 1, Fluor; Universal Imaging Corp., West Chester, PA). Before and during hypoxia, images of tubules in 10-15 randomly chosen microscopic fields (400 $\times 300 \mu \mathrm{m})$ were acquired for measurement of $\left[\mathrm{Ca}^{2+}\right]_{\mathrm{i}}$ and cell damage. All tubules which were clearly visible with a minimum area of 2,500 $\mu \mathrm{m}^{2}$ and whose borders could be clearly identified and were not covered by other tubules were used for analysis. The image- 1 software permits us to capture $\left[\mathrm{Ca}^{2+}\right]_{\mathrm{i}}$ and PI signals in individual tubules thus excluding signals generated from the spaces between tubules. Images were acquired either for measurement of $\left[\mathrm{Ca}^{2+}\right]_{i}$, cell damage, NADH associated fluorescence or for measurement of the integrity of the mitochondrial membrane (see below).

$\left[\mathrm{Ca}^{2+}\right]_{\mathrm{i}}$ was measured ratiometrically after loading tubules with the $\mathrm{Ca}^{2+}$-sensitive dye fura-2. Tubules were illuminated by a 75 watt Xenon lamp blocked alternatively with a 340-nm or 380-nm excitation filter (340 DF20, 380 DF10 Omega Optical, Brattleboro, VT). These excitation filters were changed using a computer controlled filter wheel (Imec, Charlestown, MA). To reduce photobleaching of fura-2, a neutral density filter was used. A $20 \times$ fluor objective was used (Fluor 20PH3DL, Nikon Inc.). A portion of the microscopic field was imaged onto the intensified CCD camera such that the field size was $300 \times 400$ $\mu \mathrm{m}$. Since the images had a resolution of $512 \times 512$ pixels, each pixel represented $\sim 0.5 \mu \mathrm{m}^{2}$. Emitted light, collected through a dichroic mirror with transmission above $400 \mathrm{~nm}$ (400 DCLP, Omega Optical) 
was transmitted through a 510-nm emission filter (510 DF20, Omega Optical). Cell injury was measured with the membrane-impermeable nuclear stain PI as previously described (12). Briefly, the tubules were illuminated alternatively by phase-contrast light for morphology and measurement of the tubule area and by a 75-W Xenon lamp with a 495-nm excitation filter (495 DF20, Omega Optical) for detection of PI-stained nuclei. A 10X objective (Plan10DL, NA 0.3, Nikon Inc.) was used whose wide plane of focus allowed detection of nuclei throughout the entire tubule. Emitted light, collected through a dichroic mirror with transmission above $580 \mathrm{~nm}$ (DM 580, Nikon Inc.) was transmitted through a $620 \mathrm{~nm}$ emission filter (620 DF35, Omega Optical) and enlarged with a $2 \times$ lens (magnification tugget, Nikon Inc.), which allowed the acquisition of the same final field of view as for $\left[\mathrm{Ca}^{2+}\right]_{\mathrm{i}}$ measurement $\left(300 \times 400 \mu \mathrm{m}^{2}\right)$.

$\mathrm{NADH}$-associated fluorescence (an indicator of the oxidative state of the tubules) was measured as autofluorescence in tubules which were not exposed to any fluorescent dye (18). A 357-nm excitation filter (357 DF13, Omega Optical), a dichroic mirror with transmission above 400 $\mathrm{nm}$ (400 DCLP, Omega Optical) and a $450 \mathrm{~nm}$ emission filter were used.

Integrity of the mitochondrial membrane was measured with the dye rhodamine, an indicator for mitochondrial membrane potential. In these studies the same filters employed in the measurement of nuclear staining with PI were used.

Movement of the microscope stage to other positions permitted the analysis of several other fields containing other tubules. The fields were consecutive, and thus randomly selected without bias. As many as 15 fields containing tubules from the same preparation could be studied in a particular experiment.

Quantitation of $\left[\mathrm{Ca}^{2+}\right]_{i}$ in individual tubules. Tubules $(\sim 1 \mathrm{mg} / \mathrm{ml})$ were loaded with $5 \mu \mathrm{M}$ fura-2/AM (Molecular Probes, Inc., Eugene, $\mathrm{OR}$ ) for $45 \mathrm{~min}$ at room temperature before the tubules were transferred to the perfusion chamber. A $1 \mathrm{mM}$ stock solution of fura-2/AM was prepared fresh for each experiment in dry DMSO with 5\% w/vol pluronic F127. The intracellular fura- 2 concentration was estimated by comparison with the fluorescence of various concentrations of fura- 2 pentapotassium salt in $50 \mu \mathrm{l}$ buffer sandwiched between two coverslips (19) and was found to be $\sim 15 \mu \mathrm{M}$. This concentration of fura-2 has been found not to significantly decrease $\left[\mathrm{Ca}^{2+}\right]_{\mathrm{i}}$ due to $\mathrm{Ca}^{2+}$-chelation (19). The fluorescence at the isosbestic wavelength ( $357 \mathrm{~nm}$ excitation), a measure of the fura- 2 concentration, decreased by $1.5 \% / \mathrm{min}$, probably due to leakage and/or transport of fura-2. The anion exchange inhibitor probenecid did not significantly inhibit this decrease of fura-2 (data not shown). For this reason, i.e., leakage, we terminated most of our normoxic experiments within 30 min.

The cytoplasmic localization of fura- 2 was confirmed using digitonin to selectively permeabilize tubule membranes (8). Exposure to 10 $\mu \mathrm{M}$ digitonin in the presence of $1 \mathrm{mM}$ extracellular $\mathrm{Ca}^{2+}$ abolished the fura-2 fluorescence, indicating complete release of fura- 2 from the tubules. Under this experimental condition, the mitochondrial membranes were unaffected, since the fluorescence of simultaneously loaded rhodamine (10 $\mu \mathrm{g} / \mathrm{ml}$ rhodamine), an indicator of mitochondrial membrane integrity, was not altered. It was necessary to increase the digitonin concentration to $100 \mu \mathrm{M}$ to reduce this mitochondrial associated fluorescence of rhodamine (data not shown).

The quantitative measurements with fura- 2 are also potentially complicated by the contribution of autofluorescence. However, autofluorescence (at $510 \mathrm{~nm}$ ) was at least eight times smaller than the fura-2 signal in fura-2 loaded tubules. Moreover, despite changes in NADHassociated fluorescence, autofluorescence in the fura- 2 wavelength $(510 \mathrm{~nm})$ did not change during hypoxia. To further prove that changes in autofluorescence did not influence the fura-2 signal, the fluorescence of fura-2-loaded tubules was also measured during hypoxia in the presence of the intracellular $\mathrm{Ca}^{2+}$ chelator-BAPTA. In this condition the autofluorescence of NADH associated fluorescence did not influence the fura-2 signal. For these reasons, no corrections were made for changes in autofluorescence at the fura- 2 wavelengths used for the $\left[\mathrm{Ca}^{2+}\right]_{\mathbf{i}}$ measurements.
The results are presented as the ratio of excitation at 340 and 380 $\mathrm{nm}$ (emission $510 \mathrm{~nm}$ ). To estimate $\left[\mathrm{Ca}^{2+}\right]_{i}$, the maximal ratio $\left(\mathrm{R}_{\max }\right)$ was measured in fresh tubules after addition of $10 \mu \mathrm{M}$ ionomycin (from a $1 \mathrm{mM}$ stock solution in DMSO) and the minimal ratio $\left(\mathrm{R}_{\min }\right)$ after subsequent addition of $10 \mathrm{mM}$ Tris-EGTA (from a $1 \mathrm{M}$ stock solution in $1.5 \mathrm{M}$ Tris). $R_{\max }$ and $R_{\min }$, measured in tubules after $6 \mathrm{~min}$ of hypoxia, differed $<10 \%$ from $R_{\max }$ and $R_{\min }$ obtained in normoxic tubules. Thus, indirect calibration of tubule $\left[\mathrm{Ca}^{2+}\right]_{i}$ was performed on each preparation. $\left[\mathrm{Ca}^{2+}\right]_{i}$ was calculated using the formula of Grynkiewicz using a $k_{\mathrm{d}}$ of fura-2 for $\mathrm{Ca}^{2+}$ of $224 \mathrm{nM}$ (20). Tubules usually started with a baseline $\left[\mathrm{Ca}^{2+}\right]_{\mathrm{i}}$ of $\sim 200 \mathrm{nM}$. Those tubules which started with a basal $\left[\mathrm{Ca}^{2+}\right]_{\mathrm{i}}>300 \mathrm{nM}$ were considered predamaged and were excluded from further study (usually $<5 \%$ of the preparation).

Assessment of hypoxia induced cell damage. In individual tubules, hypoxia induced cell damage was assessed with the membrane-impermeable, nuclear stain PI as previously described $(12,21)$. Briefly, images of PI fluorescence of nuclei in cells of tubules were acquired after a 1-min exposure to PI and a 1-min washout period. PI does not interfere with the $\left[\mathrm{Ca}^{2+}\right]_{\mathrm{i}}$ measurements because it is not fluorescent at the wavelengths used to measure the fura-2 fluorescence. Since PI stains nuclei only in cells that have a compromised integrity in the plasma membrane, a fluorescent nucleus represents a cell with a damaged plasma membrane. The number of PI-stained nuclei in each tubule was therefore measured under control conditions and during and after hypoxia. Cell damage was estimated by normalizing the number of PI-stained nuclei to the area of the tubules at the beginning of the experiment. Under these conditions PI-staining of 58 nuclei/10,000 $\mu \mathrm{m}^{2}$ represents damage to $100 \%$ of the cells of a tubule as described in detail elsewhere (12). The results are reported as \% damage, which is obtained by dividing the number of stained nuclei/ $10,000 \mu \mathrm{m}^{2}$ by 58 . Any individual tubule which showed significant damage $(>20 \%$ PI staining) at the beginning of the experiment was excluded from further analysis. These comprised $<5 \%$ of all tubules examined and likely represented damage induced by the isolation procedure.

In tubular suspensions which were prepared in parallel, cell damage was assessed by percent LDH release $(3,6,17,22)$, i.e., LDH activity in the supernatant as percentage of total LDH activity. We have previously found that the assessment of plasma membrane damage by PI staining and by LDH release correlate highly (12).

$A T P$ and intracellular potassium concentration. In tubule suspensions, ATP and intracellular potassium concentrations were measured by HPLC and atomic absorption spectrometry, respectively, as previously described (6).

Reagents. Fura-2/AM, pluronic F-127, PI, BAPTA-AM, and rhodamine were purchased from Molecular Probes, Inc.; ionomycin was obtained from Calbiochem Corp. (San Diego, CA); digitonin, EGTA, verapamil, and glycine were purchased from Sigma Chemical Co. (St. Louis, MO); Cell-Tak was purchased from Collaborative Research Products (Bedford, MA).

Statistical analysis. Comparisons between two groups were made by unpaired $t$ test. Single groups were analyzed by $t$ test. Multiple group comparisons were done using analysis of variance, with post-test according to Newman-Keuls. Correlation between two parameters was tested by $F$-test. A $P$ value $<0.05$ was considered the level of statistical significance. Values are expressed as means \pm SEM.

\section{Results}

Hypoxia-induced $\left[\mathrm{Ca}^{2+}\right]_{i}$ increase and cell injury. At baseline, the fura-2 ratio $(340 / 380 \mathrm{~nm})$ averaged $0.78 \pm 0.02$ reflecting a $\left[\mathrm{Ca}^{2+}\right]_{\mathrm{i}}$ of $\sim 170 \mathrm{nM}$. Hypoxia induced a progressive increase of $\left[\mathrm{Ca}^{2+}\right]_{\mathrm{i}}$ which attained significance $2 \mathrm{~min}$ after induction of hypoxia. The fura- 2 ratio reached $1.08 \pm 0.08$ after $12 \mathrm{~min}$ reflecting a $\left[\mathrm{Ca}^{2+}\right]_{\mathrm{i}}$ of $\sim 390 \mathrm{nM}$ (Fig. 1). This early, progressive increase in $\left[\mathrm{Ca}^{2+}\right]_{\mathrm{i}}$ was reversible, since $\left[\mathrm{Ca}^{2+}\right]_{\mathrm{i}}$ decreased to basal levels within 2 min of reoxygenation (Fig. 2). 


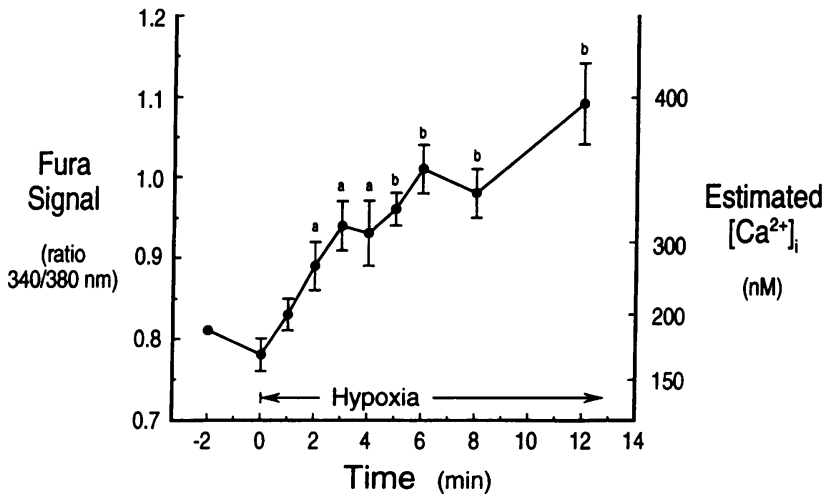

Figure 1. Hypoxia-induced increase in $\left[\mathrm{Ca}^{2+}\right]_{\mathrm{i}}$ in individual tubules. At the given timepoints, images for $\left[\mathrm{Ca}^{2+}\right]_{i}$ measurement of 10 fields (20-25 tubules per experiment) were acquired. The perfusion was switched to $\mathrm{N}_{2}$-gassed buffer at $t=0 \mathrm{~min}$. Values are given as means \pm SEM for the $340 / 380$-nm fura-2 ratio. The corresponding $\left[\mathrm{Ca}^{2+}\right]_{\mathrm{i}}$ as derived from in vivo calibration is given on the right vertical axis (6-10 experiments per data point, ${ }^{\mathrm{a}} P<0.05$; ${ }^{\mathrm{b}} \mathrm{P}<0.01$ vs. $\mathrm{O}_{2}$ perfusion).

In oxygen-perfused control tubules, PI staining at baseline averaged $7.2 \% \pm 0.5 \%$ PI-stained nuclei, with a slight increase $(16.6 \% \pm 0.7 \%, n=7)$ occurring over the next $30 \mathrm{~min}$. Hypoxia caused significant cell injury as reflected by a time-dependent increase in the number of PI-stained nuclei. However, unlike the prompt increase in $\left[\mathrm{Ca}^{2+}\right]_{i}$, the number of PI-stained nuclei did not increase significantly until after $10 \mathrm{~min}$ of hypoxia. Specifically, in the first 10 min of hypoxia PI staining increased only slightly (from $7.1 \% \pm 0.3 \%$ to $12.1 \% \pm 1.0 \%$ stained nuclei, NS, $n=19$ ). In contrast, in the succeeding $20 \mathrm{~min}$ of hypoxia the number of PI-stained nuclei increased quite significantly (20 min of hypoxia, $50.3 \% \pm 4.0 \%$ stained nuclei; $30 \mathrm{~min}$ of hypoxia; $76.0 \% \pm 3.3 \%$; both $P<0.001$ vs. $10 \mathrm{~min}$ of hypoxia, $n$ $=19$ ).

In the next set of experiments, both PI staining and $\left[\mathrm{Ca}^{2+}\right]_{i}$ were studied concurrently in the same individual tubules. $\left[\mathrm{Ca}^{2+}\right]_{i}$ was measured after $10 \mathrm{~min}$ of hypoxia and PI staining after $20 \mathrm{~min}$ of hypoxia. These timepoints were chosen to determine the correlation between increases in $\left[\mathrm{Ca}^{2+}\right]_{\mathrm{i}}$ and the

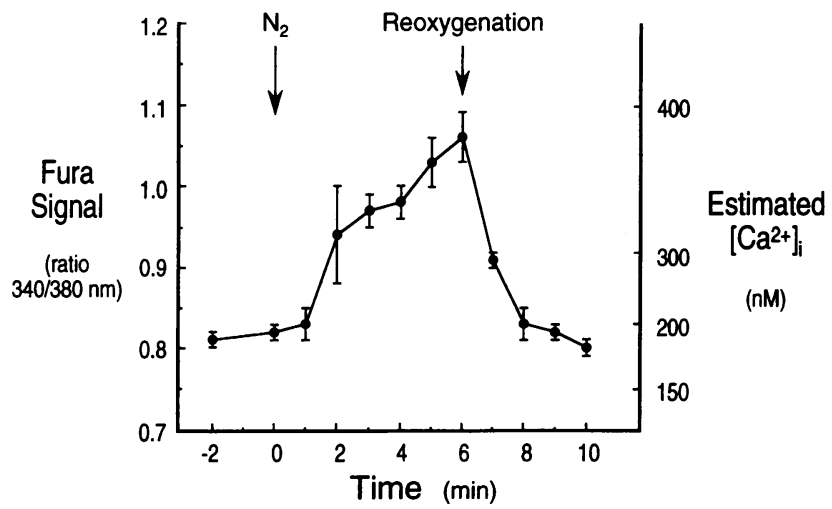

Figure 2. Prompt reversal by reoxygenation of hypoxia induced increase in $\left[\mathrm{Ca}^{2+}\right]_{\mathrm{i}}$. The protocol was the same as in Fig. 1. After $6 \mathrm{~min}$ of hypoxic perfusion, the perfusion was switched back to oxygenated perfusate (data are the mean \pm SEM of three experiments).

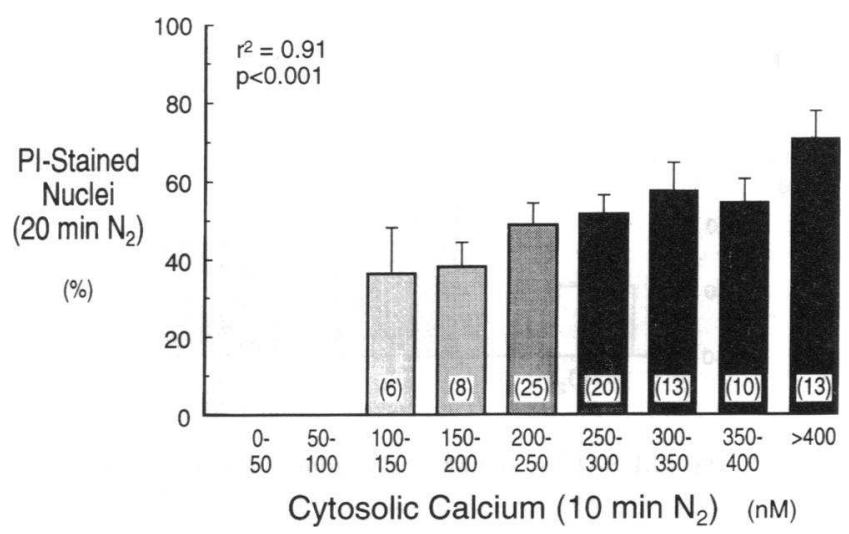

Figure 3. Correlation of $\left[\mathrm{Ca}^{2+}\right]_{\mathrm{i}}$ measured at $10 \mathrm{~min}$ and cell injury at $20 \mathrm{~min}$. After $10 \mathrm{~min}$ of hypoxia fura- 2 images were acquired and then after 20 min of hypoxia PI images were acquired from the same individual tubules. Data from 95 tubules were grouped according to the $\left[\mathrm{Ca}^{2+}\right]_{\mathrm{i}}$ at $10 \mathrm{~min}$ into seven groups and then averaged. The coefficient of variation $(\mathrm{CV})$ for the $\left[\mathrm{Ca}^{2+}\right]_{\mathrm{i}}$ data was $11 \%$ at time $0,22 \%$ at $10 \mathrm{~min} \mathrm{~N}_{2}$, and for the PI data $50 \%$ at $20 \mathrm{~min} \mathrm{~N}_{2}$. Values are given as means \pm SEM. $r^{2}=0.91, P<0.001$. The number of tubules in each group is displayed in parenthesis on each bar.

subsequent magnitude of cell damage. Cell injury measured after $20 \mathrm{~min}$ of hypoxia correlated with the $\left[\mathrm{Ca}^{2+}\right]_{\mathrm{i}}$ level at 10 min of hypoxia (Fig. 3). $\left[\mathrm{Ca}^{2+}\right]_{i}$ studies were not carried further than 10 min of hypoxia since this was the last timepoint where sufficient intracellular fura-2 was present to make a valid $\left[\mathrm{Ca}^{2+}\right]_{\mathrm{i}}$ measurement and where the tubules were virtually undamaged (as assessed by PI staining).

Effect of BAPTA on hypoxia-induced $\left[\mathrm{Ca}^{2+}\right]_{i}$ increase and cell injury. To determine the dose of BAPTA required to block the rise in $\left[\mathrm{Ca}^{2+}\right]_{\mathrm{i}}$ induced by hypoxia, varying doses of BAPTA $(25-100 \mu \mathrm{M})$ were tested for effectiveness against the $\left[\mathrm{Ca}^{2+}\right]_{\mathrm{i}}$ rise. Only $100 \mu \mathrm{M}$ BAPTA was effective at maintaining the $\left[\mathrm{Ca}^{2+}\right]_{i}$ levels below baseline through $10 \mathrm{~min}$ of hypoxia (Fig. 4). Loading with $100 \mu \mathrm{M}$ BAPTA did not alter initial PI staining $(8.8 \pm 0.3 \%$ vs. $7.8 \pm 0.7 \%$, NS), or LDH release from nor-

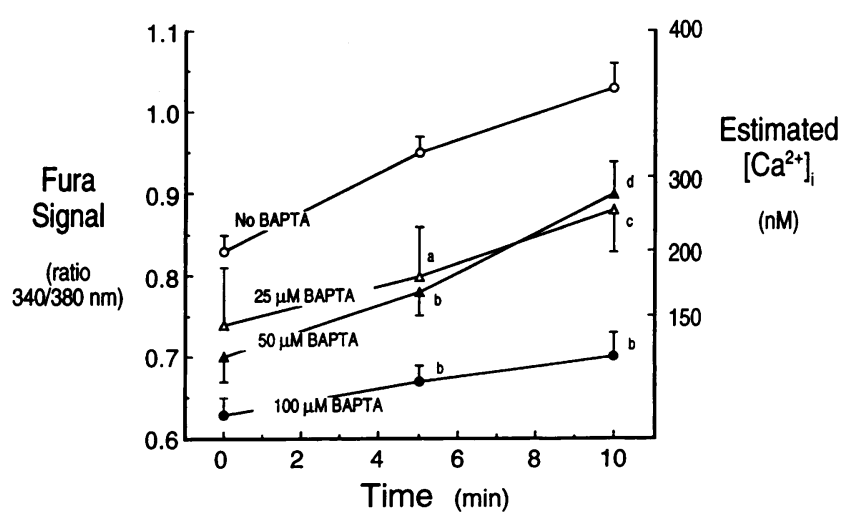

Figure 4. Effect of the intracellular $\mathrm{Ca}^{2+}$-chelator BAPTA on $\left[\mathrm{Ca}^{2+}\right]_{\mathrm{i}}$ during hypoxia. Varying doses from 0 to $100 \mu \mathrm{M}$ BAPTA were loaded into tubules, and the $\left[\mathrm{Ca}^{2+}\right]_{i}$ was measured at 0,5 , and $10 \mathrm{~min}$ of hypoxia. Basal (time 0 ) levels of $\left[\mathrm{Ca}^{2+}\right]_{i}$ are reduced by BAPTA in a dose-dependent manner (mean \pm SEM with 15-20 tubules per experiment). ${ }^{\mathrm{a}} P<0.01$; ${ }^{\mathrm{b}} P<0.001$ vs. no BAPTA; ${ }^{\mathrm{c} P}<0.05$; $^{\mathrm{d}} P<0.01$ vs. $100 \mu \mathrm{M}$ BAPTA. 


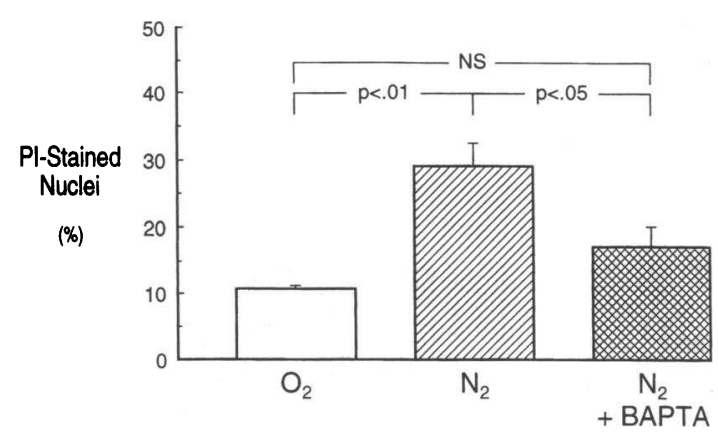

Figure 5. $100 \mu \mathrm{M}$ BAPTA signfificantly reduces membrane injury after 15 min of hypoxia. PI-stained nuclei in tubules after $15 \mathrm{~min}$ of normoxia (open bar), 15 min of hypoxia (hatched bar), and after 15 min of hypoxia in tubules loaded with $100 \mu \mathrm{M}$ BAPTA (cross-hatched bar). Values are given as means $\pm \operatorname{SEM}(n=6-10$ experiments).

moxic tubules $(10.0 \pm 0.4 \%$ vs. $10.8 \pm 0.9 \%$, NS). BAPTA at the $100 \mu \mathrm{M}$ dose virtually afforded complete membrane protection during $15 \mathrm{~min}$ of hypoxia (Fig. 5). However, at later timepoints of hypoxia, the protection afforded by BAPTA was significant although not complete $(31 \pm 3.1 \%$ vs. $50 \pm 4.5 \%$ PI staining at $20 \mathrm{~min}$ hypoxia, $P<0.01 ; 55.7 \pm 5.2 \%$ vs. $73.1 \pm 5.7 \% \mathrm{PI}$ staining at $30 \mathrm{~min}$ of hypoxia, $P<0.05$; with and without BAPTA, respectively). At $20 \mathrm{~min}$ of hypoxia, it was not possible to determine whether BAPTA maintained a low $\left[\mathrm{Ca}^{2+}\right]_{\mathrm{i}}$ since the fura- 2 had leaked out of the tubules. The $\left[\mathrm{Ca}^{2+}\right]_{\mathrm{i}}$ at 10 min of hypoxia in single tubules loaded with varying doses of BAPTA (25-100 $\mu \mathrm{M})$ was significantly correlated with the cell damage as assessed by PI staining at 20 min of hypoxia (Fig. 6).

Effect of BAPTA on ATP and intracellular potassium. The protection of BAPTA against hypoxia-induced membrane damage as assessed by PI staining occurred in spite of a failure of BAPTA to protect against the hypoxia-induced decrease in

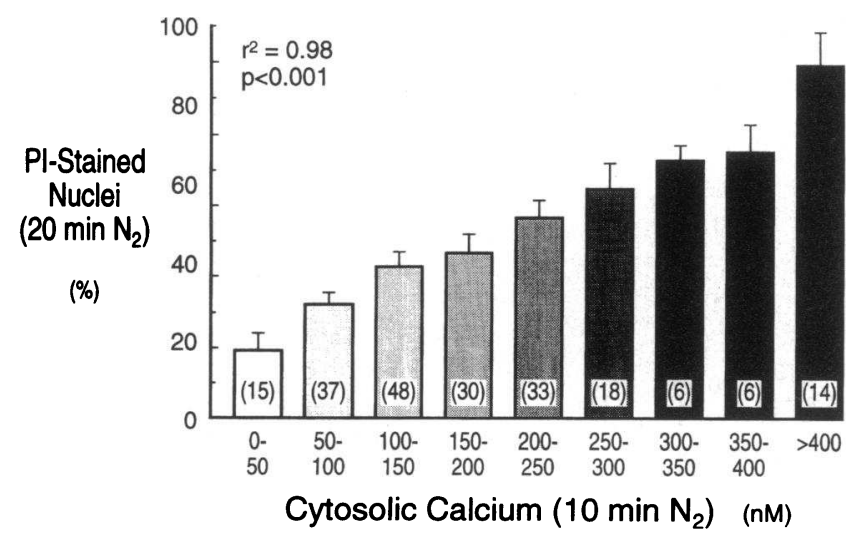

Figure 6. Correlation of BAPTA effect on $\left[\mathrm{Ca}^{2+}\right]_{\mathrm{i}}$ and cell injury. 12 experiments were performed in which tubules were loaded with varying doses of BAPTA/AM $(25 \mu \mathrm{M}, n=3 ; 50 \mu \mathrm{M}, n=6 ; 100 \mu \mathrm{M}, n$ $=3$. After $10 \mathrm{~min}$ of hypoxia fura- 2 images were acquired and then after 20 min of hypoxia PI images were acquired from the same individual tubules. Data from 207 tubules were grouped according to the $\left[\mathrm{Ca}^{2+}\right]_{\mathrm{i}}$ at $10 \mathrm{~min}$ in nine groups and then averaged. Values are given as means \pm SEM. $r^{2}=0.98, P<0.001$. The number of tubules in each group are displayed in parentheses in each bar. 63\% (130/207) of the tubules had $\left[\mathrm{Ca}^{2+}\right]_{\mathrm{i}}$ at $10 \mathrm{~min}$ that was $<200 \mathrm{nM}$. This contrasts to only $15 \%(14 / 95)$ of tubules that had $\left[\mathrm{Ca}^{2+}\right]_{\mathrm{i}}<200 \mathrm{nM}$ in untreated tubules (Fig. 3). cellular ATP and $\mathrm{K}^{+}$(measured in tubule suspensions). In fact, after $15 \mathrm{~min}$ of hypoxia the BAPTA-treated tubules had somewhat lower cellular ATP $(1.3 \pm 0.3$ vs. $2.0 \pm 0.3 \mathrm{nmol} / \mathrm{mg}$ protein, NS) and lower $\mathrm{K}^{+}(97 \pm 9$ vs. $127 \pm 5 \mathrm{nmol} / \mathrm{mg}$ protein, $P$ $<0.01$ ) than the non-BAPTA treated tubules.

Effect of verapamil or glycine on hypoxia-induced $[\mathrm{Ca} 2+]_{i}$ increase and cell injury. As noted above, PI staining is minimal after $10 \mathrm{~min}$ of hypoxia and increases markedly by $20 \mathrm{~min}$ of hypoxia. Verapamil $(100 \mu \mathrm{M})$ did not alter either the increase in $\left[\mathrm{Ca}^{2+}\right]_{\mathrm{i}}$ at $10 \mathrm{~min}$ of hypoxia or the subsequent PI staining at $20 \mathrm{~min}$ of hypoxia (data not shown). Glycine ( $2 \mathrm{mM})$ did not alter the rise in $\left[\mathrm{Ca}^{2+}\right]_{\mathrm{i}}$ during hypoxia $(250 \pm 5$ vs. $257 \pm 27 \mathrm{nM}$ without glycine at $5 \mathrm{~min}$ of hypoxia, NS). However, complete membrane protection was afforded as assessed by PI staining (Fig. 7). This protection occurred even when the glycine was added after $10 \mathrm{~min}$ of hypoxia, i.e., after $\left[\mathrm{Ca}^{2+}\right]_{i}$ increased $\left(25.2 \pm 2.6 \% \mathrm{PI}\right.$ at $30 \mathrm{~min} \mathrm{~N}_{2}$ vs. $73.1 \pm 5.7 \%$ without glycine, $P$ $<0.01)$. As with BAPTA, however, glycine does not protect against the fall in ATP or $\mathrm{K}^{+}(17)$.

Effect of low extracellular $\mathrm{Ca}^{2+}$ on hypoxia-induced $\left[\mathrm{Ca}^{2+}\right]_{i}$ increase. To ascertain the source of $\mathrm{Ca}^{2+}$ for the hypoxia-induced rise in $\left[\mathrm{Ca}^{2+}\right]_{i}$, the tubule perfusate was changed to a low $\mathrm{Ca}^{2+}$ buffer $3 \mathrm{~min}$ before the induction of hypoxia. The low $\mathrm{Ca}^{2+}$ buffer (1 mM EGTA/0.7 $\mathrm{mM} \mathrm{Ca}^{2+}$ ) reduced the free $\mathrm{Ca}^{2+}$ outside of the tubules to $\sim 200 \mathrm{nM}$. This reduction of $\mathrm{Ca}^{2+}$ outside of the tubules completely prevented the rise in $\left[\mathrm{Ca}^{2+}\right]_{\mathrm{i}}$ during hypoxia $\left(193 \pm 15 \mathrm{nM}\right.$ at $10 \mathrm{~min} \mathrm{~N}_{2}$ vs. $187 \pm 12 \mathrm{nM}$ at time $0, n=10$ ). Ionomycin addition confirmed that the intracellular pools of $\mathrm{Ca}^{2+}$ were not depleted by this low $\mathrm{Ca}^{2+}$ buffer.

\section{Discussion}

$\mathrm{Ca}^{2+}$ ions have been proposed to be one of the major contributors to the functional, biochemical, and morphological derangements that characterize ischemic or hypoxic insults to in situ kidneys or isolated perfused kidneys (2). This proposal is based partly on the protective effects in $\operatorname{dog}(23,24)$, rat $(25,26)$, and human kidneys $(27,28)$ of intrarenal or systemic infusions of various, chemically dissimilar $\mathrm{Ca}^{2+}$ channel blockers (CCB). It has been suggested, however, that much of the functional renal protection could be explained by renal vascular effects of CCB with the cytoprotective effects on tubular function occurring secondary to improved perfusion. Verapamil and diltiazem,

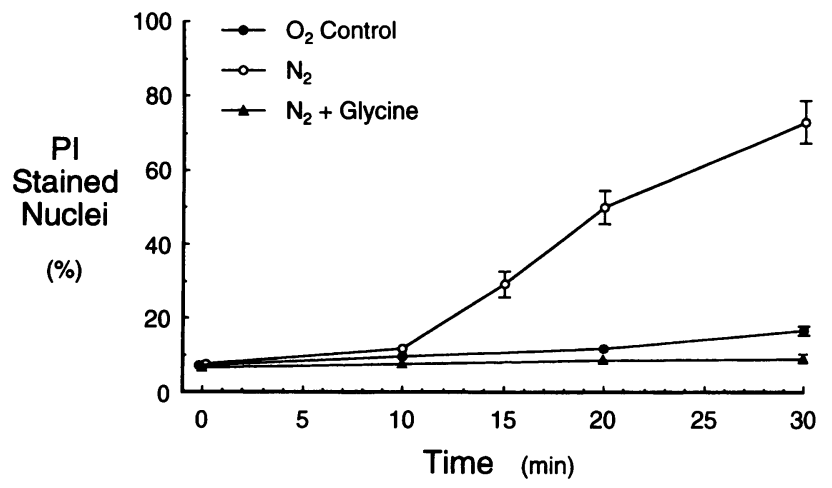

Figure $7.2 \mathrm{mM}$ glycine completely protects tubules from membrane damage during hypoxic perfusion. PI staining during normoxia (•), hypoxia (o), and hypoxia in the presence of $2 \mathrm{mM}$ glycine ( $\triangle$ ). Data are given as means $\pm \operatorname{SEM}(n=6-10$ experiments). 
for example, correct the impaired autoregulation of renal blood flow and reduce the hypersensitivity to renal nerve stimulation observed in ischemic rat kidneys (26). These vascular effects in intact kidneys make it virtually impossible to attribute unambiguously a direct protective effect of CCB on renal tubules. However, since other renal vasodilators such as acetylcholine or bradykinin, do not afford functional or tubular protection, it has been suggested that the CCB may directly prevent $\mathrm{Ca}^{2+}$ mediated renal tubule injury during oxygen deprivation (2).

Nephron segments have been studied in isolation, either by using freshly isolated tubules in suspension or tubules in primary culture, to evaluate the possibility of a direct tubular protection by $\mathrm{CCB}$ and to understand the role of $\mathrm{Ca}^{2+}$ ions in mediating renal tubule cell injury. In this regard we have previously performed studies in freshly isolated rat renal proximal tubule preparations $(3,6,17)$ and in primary cultures of rabbit tubules $(29,30)$ to define the role of $\mathrm{Ca}^{2+}$ in mediating the oxygen deprivation injury. The results have shown that hypoxia or anoxia in rat proximal tubules is accompanied by an increased $\mathrm{Ca}^{2+}$ influx from the media into the cells and an elevation in $\mathrm{LDH}$ release as an index of cell membrane damage (3). Chemically dissimilar CCB, verapamil or flunarizine, prevented the increased rate of $\mathrm{Ca}^{2+}$ influx and $\mathrm{LDH}$ release after $10 \mathrm{~min}$ but not $20 \mathrm{~min}$ of hypoxia (3). In other studies, when $\mathrm{Ca}^{2+}$ entry into primary cultures of anoxic rabbit tubules was prevented by CCB or its effects blocked by calmodulin inhibitors, cell viability was also increased (30). Finally, with removal of $\mathrm{Ca}^{2+}$ either from the media bathing rabbit primary cultures for the first 2 hours of reoxygenation (29) or from the media containing suspensions of rat proximal tubules during hypoxia (6) enhanced cell viability resulted. Together, these results supported the hypothesis that $\mathrm{Ca}^{2+}$ ions enter hypoxic or anoxic tubules and lead to an increase in $\left[\mathrm{Ca}^{2+}\right]_{\mathrm{i}}$ which, via calmodulin activation or other mechanisms, may initiate pathways leading to cell injury or cell death. It is known, however, that tubular necrosis during renal ischemia in vivo or hypoxic injury in vitro either in tubule suspensions or in primary cultures is a heterogenous phenomena. Thus, it has been difficult to examine conclusively whether the onset of the pertubations in cellular $\mathrm{Ca}^{2+}$ kinetics antedates, coincides with or is a sequelae of cellular membrane damage.

In the present study we have isolated proximal tubules from normal rat kidneys by percoll gradient centrifugation and studied these preparations concurrently both with the conventional technique of tubule suspensions and in a customized perfusion chamber using video microscopy to study individual tubules. The perfusion chamber used in the video imaging system and the dissimilar fluorescent wavelengths optimized for fura- 2 and PI permits the quantitative assessment of time-related changes in cytosolic-free $\mathrm{Ca}^{2+}$ and membrane permeability to PI in the same tubule in response to an hypoxic insult. This technology also permitted us to identify tubules damaged, presumably by the isolation procedure, and thereby to reduce the degree of heterogeneity associated with suspension measurements.

The perfusion chamber used with the video imaging system also provides control over several variables which may complicate interpretation of results obtained with other methods. The perfusion chamber is a flow through system which prevents accumulation of waste products, continuously supplies nutrients and maintains $\mathrm{pO}_{2}$ at constant levels during normoxia and at constant low levels during hypoxia. $\mathrm{pH}, \mathrm{PCO}_{2}$, and temperature are also maintained constant throughout the experi- ment. Thus, the perfusion system provides a very controlled experimental environment whereby $\mathrm{O}_{2}$ concentration can be singularly altered during the study of hypoxia-induced tubule injury.

The present results obtained by the video imaging of tubules in the perfusion chamber demonstrate that steady state hypoxia is accompanied by a prompt increase (significant at 2 min) in cytosolic free $\mathrm{Ca}^{2+}$. The increase in cytosolic free $\mathrm{Ca}^{2+}$ precedes the appearance of membrane damage as assessed by propidium iodide nuclear staining ( $>10 \mathrm{~min}$ ). Finally, this increase in $\left[\mathrm{Ca}^{2+}\right]_{\mathrm{i}}$ associated with hypoxia is promptly reversible with reoxygenation. This latter observation is important since, if cytosolic free $\mathrm{Ca}^{2+}$ is increased only after lethal cell membrane damage, reoxygenation should not have normalized $\left[\mathrm{Ca}^{2+}\right]_{\mathrm{i}}$. The low extracellular $\mathrm{Ca}^{2+}$ experiments indicated that the rise in $\left[\mathrm{Ca}^{2+}\right]_{\mathrm{i}}$ is primarily due to $\mathrm{Ca}^{2+}$ entry into the cell from the extracellular compartment.

Changes in $\left[\mathrm{Ca}^{2+}\right]_{\mathrm{i}}$ during hypoxia are likely influenced not only by changes in $\mathrm{Ca}^{2+}$ influx and efflux rates, but also by changes in intracellular buffering of $\mathrm{Ca}^{2+}$ by organelles such as mitochondria (4). The present observation demonstrated that verapamil treatment did not reduce $\left[\mathrm{Ca}^{2+}\right]_{i}$ at $10 \mathrm{~min}$ of hypoxia, even though in an earlier study of proximal tubules in suspension ${ }^{45} \mathrm{Ca}^{2+}$ influx rate has been shown to be lowered by verapamil at $10 \mathrm{~min}$ of hypoxia (3). The differences between ${ }^{45} \mathrm{Ca}^{2+}$ influx measurements and $\left[\mathrm{Ca}^{2+}\right]_{\mathrm{i}}$ measurements might be due to verapamil's effect to block mitochondrial $\mathrm{Ca}^{2+}$ buffering (31). Thus, verapamil treatment reduces total tissue $\mathrm{Ca}^{2+}$ burden, lowers mitochondrial $\mathrm{Ca}^{2+}$ overload, reduces $\mathrm{Ca}^{2+}$ influx rate, and affords protection but may not alter $\left[\mathrm{Ca}^{2+}\right]_{\mathrm{i}}$ during $10 \mathrm{~min}$ of hypoxia. A possible explanation is that the protective effect of verapamil against hypoxia in tubule suspensions has recently been found to occur in the absence of extracellular $\mathrm{Ca}^{2+}(6)$. Taken together, therefore, protection against hypoxia-induced injury in proximal tubule suspensions by verapamil involves more than a blockade of an increase in $\mathrm{Ca}^{2+}$ influx or a rise in $\left[\mathrm{Ca}^{2+}\right]_{i}$.

The video imaging system/perfusion chamber allowed assessment of the magnitude and timing of alterations in cytosolic free $\mathrm{Ca}^{2+}$ and the development of PI-detectable membrane injury in the same tubules and the same cells within the tubule. This approach is unique and is extremely important since, as in other systems, the response to hypoxia is heterogenous $(12,29)$. In the present study using the video imaging system/perfusion chamber, there was a strong correlation between the early rise in cytosolic free $\mathrm{Ca}^{2+}$ at $10 \mathrm{~min}$ of hypoxia and the subsequent nuclear PI staining in tubule cells at $20 \mathrm{~min}$ of hypoxia. Some injury however was observed in tubules which did not experience a detectable rise in $\left[\mathrm{Ca}^{2+}\right]_{\mathrm{i}}$ by $10 \mathrm{~min}$ of hypoxia, suggesting an additional role for $\mathrm{Ca}^{2+}$-independent mechanisms as well in cell injury.

The mechanism whereby increases in cytosolic free $\mathrm{Ca}^{2+}$ could lead to cell membrane injury remains to be defined; however, evidence has been accumulated that activation of phospholipase $A_{2}$ may occur during hypoxia in rat proximal tubules (32) and lead to free fatty acid accumulation (17). In this regard, there are isoforms of phospholipase $\mathrm{A}_{2}$ which are known to be $\mathrm{Ca}^{2+}$ dependent. In any case, if the rise in $\left[\mathrm{Ca}^{2+}\right]_{\mathrm{i}}$ is of pathogenetic importance in hypoxia-induced tubular injury then attenuation of this rise in $\left[\mathrm{Ca}^{2+}\right]_{i}$ should afford some protection. Studies were therefore performed in which the $\mathrm{Ca}^{2+}$ chelator BAPTA attenuated the rise in $\left[\mathrm{Ca}^{2+}\right]_{i}$ during hypoxia. 
$100 \mu \mathrm{M}$ BAPTA was more effective than 50 or $25 \mu \mathrm{M}$. In this setting, either using tubules in suspension or the video imaging system with the perfusion chamber, the evidence of membrane damage in these systems, namely LDH release and PI nuclear staining, respectively, was significantly decreased.

The protection against membrane damage which was afforded by BAPTA was not accompanied by reversal of the fall in cellular ATP and $\mathrm{K}^{+}$which is a consistent accompaniment of hypoxia. In fact, ATP levels appeared to be slightly lower in hypoxic BAPTA-treated tubules compared to hypoxia alone. Others have also reported an effect of BAPTA to decrease cellular ATP (33). Thus, it is all the more impressive that in spite of a modest detrimental effect of BAPTA to normal tubules, BAPTA treatment delayed the onset of hypoxia-induced membrane damage.

While virtually complete protection against hypoxia-induced membrane damage was observed at $15 \mathrm{~min}$ of hypoxia in tubules treated with BAPTA, significant but not complete membrane damage persisted after 20 and 30 min of hypoxia as assessed by PI staining. It is therefore not unreasonable to invoke cytosolic $\mathrm{Ca}_{2}{ }^{+}$-independent injury mechanism(s) at 20 min or longer of hypoxia. The conclusion that cytosolic $\mathrm{Ca}^{2+}$-independent mechanisms accounted for part of the hypoxic injury at $20 \mathrm{~min}$ which occurred in spite of $100 \mu \mathrm{M}$ BAPTA was, however, speculative for the following reasons. When the membrane damage to the proximal tubules occurred not only did the normally membrane-impermeable dye PI enter the cells but the fura- 2 leaked out of the cell. This made it impossible to judge whether the $100 \mu \mathrm{M}$ BAPTA was effective in completely preventing the known progressive rise in $\left[\mathrm{Ca}^{2+}\right]_{i}$ during continued hypoxia (see Fig. 1).

Another approach was undertaken with the perfusion technique to further examine the relationship between $\left[\mathrm{Ca}^{2+}\right]_{i}$ changes and membrane damage. Glycine has been shown by several laboratories including our own to afford protection against hypoxia-induced injury (15-17). Studies with the perfusion technique demonstrated nearly complete protection with glycine after $30 \mathrm{~min}$ of hypoxia in spite of a rise in $\left[\mathrm{Ca}^{2+}\right]_{i}$. These results demonstrated that glycine protects rat proximal tubules from hypoxic injury independent of, or downstream from, the rise in $\left[\mathrm{Ca}^{2+}\right]_{i}$. Such a downstream effect could be a glycine-mediated attenuation of the injury induced by calcium activation of phospholipases or proteases.

In summary, using a video imaging system and a perfusion chamber the temporal and quantitative responses to hypoxia were evaluated in individual rat proximal tubules and tubule cells. The perfusion chamber system allowed for the meticulous control of $\mathrm{PO}_{2}, \mathrm{PCO}_{2}$, and $\mathrm{pH}$ and avoided the accumulation of metabolic products or deficiency of nutrients. The results clearly demonstrated that a significant rise in cytosolic free $\mathrm{Ca}^{2+}$ occurred within the first 2 min of hypoxia and preceded the onset of membrane damage as assessed by PI nuclear staining. A pathogenetic role for the rise in cytosolic-free $\mathrm{Ca}^{2+}$ was implicated by the observation of a significant correlation between an early rise in $\left[\mathrm{Ca}^{2+}\right]_{i}$ and subsequent membrane damage. Moreover, protection against hypoxia-induced membrane injury was demonstrable when the elevation in $\left[\mathrm{Ca}^{2+}\right]_{i}$ was prevented or attenuated by the intracellular chelator, BAPTA. The present results therefore appear to provide the most compelling evidence to date for a role of increasing cytosolic calcium in the initiation of hypoxia-induced rat proximal tubule damage. Events downstream from the rise in $\left[\mathrm{Ca}^{2+}\right]_{\mathrm{i}}$ or indepen- dent of a rise in $\left[\mathrm{Ca}^{2+}\right]_{i}$ are however involved in the protective effect of glycine.

\section{Acknowledgements}

The authors would like to thank Dr. Raphael Nemenoff for valuable discussions, Carolyn Burke for technical illustrations, Tracy Curren for technical assistance, and Norma Worland and Verlyn Mileger for secretarial assistance.

This work was supported by a grant from the National Institutes of Health (DK 35098). Dr. Andreas Kribben was supported by a grant from the Deutsche Forschungsgemeinschaft (Kr 1108/1-1), Dr. Jack Wetzels was supported by a grant from the Dutch Kidney Foundation (C90.0958), Dr. Luis Yu was supported by a grant from FAPESP, Brazil $(91 / 2148-4)$.

\section{References}

1. Burke T. J., and R. W. Schrier. 1992. Pathophysiology of cell ischemia. In Diseases of the Kidney. R. W. Schrier and C. W. Gottschalk, editors. Little, Brown, \& Co., Boston. 1257-1286.

2. Schrier, R. W., P. E. Arnold, V. J. Van Putten, and T. J. Burke. 1987. Cellular calcium in ischemic acute renal failure: role of calcium entry blockers. Kidney Int. 32:313-321.

3. Almeida, A. R. P., D. Bunnachak, M. Burnier, J. F. M. Wetzels, T. J. Burke, and R. W. Schrier. 1992. Time-dependent protective effects of calcium channel blockers on anoxia- and hypoxia-induced proximal tubule injury. J. Pharmacol. Exp. Ther. 260:526-532.

4. Takano, T., S. P. Soltoff, S. Murdaugh, and L. J. Mandel. 1985. Intracellular respiratory dysfunction and cell injury in short-term anoxia of rabbit renal proximal tubules. J. Clin. Invest. 76:2377-2384.

5. Weinberg, J. M. 1985. Oxygen deprivation-induced injury to isolated rabbit kidney tubules. J. Clin. Invest. 76:1193-1208.

6. Wetzels, J. F. M., L. Yu, X. Wang, A. Kribben, T. J. Burke, and R. W. Schrier. 1993. Calcium modulation and cell injury in isolated rat proximal tubules. J. Pharmacol. Exp. Ther. 267:176-180.

7. Phelps, P. C., and M. W. Smith. 1989. Cytosolic ionized calcium and bleb formation after acute cell injury of cultured rabbit renal tubule cells. Lab. Invest. 60:630-642.

8. Weinberg, J. M., J. A. Davis, N. F. Roeser, and M. A. Venkatachalam. 1991. Role of increased cytosolic free calcium in the pathogenesis of rabbit proximal tubule cell injury and protection by glycine or acidosis. J. Clin. Invest. 87:581-590.

9. Weinberg, J. M.. 1991. The cell biology of ischemic renal injury. Kidney Int. 39:476-500.

10. Jacobs, W. R., M. Sgambati, G. Gomez, P. Vilaro, M. Higdon, P. D. Bell, and L. J. Mandel. 1991. Role of cytosolic $\mathrm{Ca}^{2+}$ in renal tubule damage induced by anoxia. Am. J. Physiol. 260:C545-C554.

11. Jacobs, W. R., C. M. Ferrari, P. C. Brazy, and L. J. Mandel. 1990. Cytosolic free calcium regulation in renal tubules from spontaneously hypertensive rats. Am. J. Physiol. 258:F175-F182.

12. Kribben, A, J. F. M. Wetzels, E. D. Wieder, T. J. Burke, and R. W. Schrier. 1993. New technique to assess hypoxia-induced cell injury in individual isolated renal tubules. Kidney Int. 43:464-469.

13. Lemasters, J. J., J. DiGuiseppi, A.-L. Nieminen, and B. Herman. 1987 Blebbing, free $\mathrm{Ca}^{++}$, and mitochondrial membrane potential preceding cell death in hepatocytes. Nature (Lond.). 325:78-81.

14. Smith, M. W., P. C. Phelps, and B. F. Trump. 1992. Injury-induced changes in cytosolic $\mathrm{Ca}^{2+}$ in individual rabbit proximal tubule cells. Am. J. Physiol. 262:F647-F655.

15. Weinberg, J. M., J. A. Davis, M. Abarzua, T. Kiani, and R. Kunkel. 1990 Protection by glycine of proximal tubules from injury due to inhibitors of mitochodrial ATP production. Am. J. Physiol. 258(6 Part 1):C1127-1140.

16. Mandel, L. J., R. G. Schnellmann, W. R. Jacobs. 1990. Intracellular glutathione in the protection from anoxic injury in renal proximal tubules. $J$. Clin. Invest. 85:316-324.

17. Wetzels, J. F. M., X. Wang, P. E. Gengaro, R. A. Nemenoff, T. J. Burke, and R. W. Schrier. 1993. Glycine protection against hypoxic but not phospholipase A2 induced injury in rat proximal tubules. Am. J. Physiol. 264:94-99.

18. Balaban, R. S., and L. J. Mandel. 1988. Metabolic substrate utilization by rabbit proximal tubule. An NADH fluorescence study. Am. J. Physiol. 254:F404 F416.

19. Tsien, R. Y., and A. T. Harooturian. 1990. Practical design criteria for a dynamic ratio imaging system. Cell Calcium. 11: 93-109. 
20. Grynkiewicz, G. M., M. Poenie, and R. Y. Tsien. 1985. A new generation of $\mathrm{Ca}^{2+}$ indicators with greatly improved fluorescence properties. J. Biol. Chem. 260:3440-3450.

21. Sasaki D. T., S. E. Dumas, and E. G. Engleman. 1987. Discrimination of viable and non-viable cells using propidium iodide in two color immunofluorescence. Cytometry. 8:413-420.

22. Bergemeyer, H. V.: Methods in Enzymatic Analysis. Academic Press, New York, 1974. 574-589 pp.

23. Burke, T. J., P. E. Arnold, J. A. Gordon, R. E. Bulger, D. C. Dobyan, and R. W. Schrier. 1984. Protective effect of intrarenal calcium membrane blockers before and after renal ischemia. J. Clin. Invest. 74:1830-1841.

24. Wagner, K., G. Schultze, M. Molzahn, and H. H. Neumeyer. 1986. The influence of long-term infusion of the calcium antagonist diltiazem on postischemic acute renal failure in conscious dogs. Klin. Wochenschr. 64:135-140.

25. Goldfarb, D., A. Iaina, I. Serbon, S. Gavendo, S. Kaoupler, and H. E. Eliahou. 1983. Beneficial effect of verapamil in ischemic acute renal failure in the rat. Proc. Soc. Exp. Biol. Med. 172:389-392

26. Conger, J. D., J. B. Robinette, and R. W. Schrier. 1988. Smooth muscle calcium and endothelium derived relaxing factor in the abnormal vascular response of acute renal failure. J. Clin. Invest. 82:532-537.
27. Duggan, K. A., G. J. MacDonald, J. A. Charlesworth. 1985. Verapamil prevents post-transplant oliguric renal failure. Clin. Nephrol. 289-291.

28. Neumayer, H.-H., and K. Wagner. 1987. Prevention of delayed graft function in cadaver kidney transplants by diltiazem: outcome of two prospective, randomized clinical trials. J. Cardiovasc. Pharmacol. 10 (Suppl. 10):S170-S177.

29. Wilson, P. D., and R. W. Schrier. 1986. Nephron segment and calcium as determinants of anoxic cell death in primary renal cell cultures. Kidney Int. 29:1172-1179.

30. Schwertschlag, U., R. W. Schrier, and P. D. Wilson. 1986. Beneficial effects of calcium channel blockers and calmodulin binding drugs on in vitro renal cell anoxia. J. Pharmacol. Exp. Ther. 238: 119-124.

31. Kohda, C., and Gemba M. 1979. Effect of verapamil on the calcium and magnesium transports of rat kidney cortex mitochondria. Jpn. J. Pharmacol. 29:745-751.

32. Choi, K. H., R. A. Nemenoff, and R. W. Schrier. 1992. Hypoxia induces changes in phospholipase A2 in rat proximal tubules: evidence for multiple forms. J. Am. Soc. Nephrol. 3:704. (Abstr.)

33. Tojyo, Y., and Y. Matsumoto. 1990. Inhibitory effects of loading with the calcium-chelator 1,2-bis(o-aminophenoxy)ethane-N,N,N, $N^{\prime}$-tetraacetic acid (BAPTA) on amylase release and cellular ATP level in rat parotid cells. Biochem. Pharmacol. 39:1775-1779. 